\title{
A educação popular em tessitura com as políticas públicas: ponderando estranhamentos e possibilidades ${ }^{1}$
}

Paulo Alfredo Schönardie ${ }^{2}$

\section{Resumo}

A educação popular se constrói histórica e organicamente, na América Latina, estreitamente associada à conjuntura social e política. Ela se apresenta como um movimento que produz um pensamento pedagógico latino-americano, em que sujeitos e coletivos elaboram experiências educativas com intencionalidade emancipatória, construindo autonomia, tornando-se sujeitos de sua história. Na atualidade, é desafiada pelo seu reconhecimento como política pública através de um marco de referência, que é aqui apresentado e criticamente analisado. Com o marco de referência surgem estranhamentos e possibilidades para a educação popular. Pela apresentação de paralelos com a educação do campo, com a pedagogia social e com a educação em saúde, que compartilham fundamentos teóricos e procedimentos metodológicos com a educação popular, são percebidos seus possíveis caminhos na condição de política pública. O texto culmina ponderando estranhamentos e possibilidades que se apresentam à educação popular agora que ela possui o respaldo de penetrar nos espaços oficiais de educação e política, podendo humanizá-los.

\section{Palavras-chave}

Educação Popular. Política Pública. Autonomia. Bases HistóricoConceituais da Educação Popular. Educação do Campo.

1. Uma versão anterior deste artigo foi apresentada no GT Educação Popular, na Reunião da Associação Nacional de Pós-Graduação e Pesquisa em Educação (Anped), no ano de 2015.

2. Doutor em Ciências Econômicas e Sociais pela Universität Hamburg, Alemanha, com revalidação em Ciências Sociais pela Universidade Estadual de Campinas, São Paulo, Brasil; professor colaborador na Universidade Regional do Noroeste do Estado do Rio Grande do Sul, Brasil; pesquisador no grupo de pesquisa Estudos de Educação Popular, Movimentos e Organizações Sociais (GEEP/CNPq). E-mail: pschonardie@gmail.com. 


\title{
Popular education interlaced with public policies: weighting misunderstandings and possibilities
}

Paulo Alfredo Schönardie*

\begin{abstract}
Popular education is historically and organically built in Latin America, closely related to the social and political context. It comes as a movement that produces a pedagogical Latin American thinking in which individuals and collective subjects create educational experiences focused on emancipatory intentionality, developing autonomy, becoming subjects of their own history. Nowadays, it is challenged by its recognition as a public policy by means of a reference framework, critically discussed and analyzed in this study. Misunderstandings and possibilities arise to popular education from the reference framework. By comparing studies to countryside education, social pedagogy and health education, sharing theoretical grounds and methodological procedures with popular education, possible solutions can be perceived in its condition as public policy. The text leads to weighting misunderstandings and possibilities to popular education as it counts on the necessary support to break into official spaces of education and politics capable of humanizing them.
\end{abstract}

\section{Keywords}

Popular Education. Public Policy. Autonomy. Historical Conceptual Grounds of Popular Education. Countryside Education.

\footnotetext{
* PhD in Economics and Social Sciences, University of Hamburg, Germany, with revalidation in Social Sciences, Campinas State University, São Paulo, Brasil; associate professor at Regional University of the Northwest of the State of Rio Grande do Sul, Brazil; researcher in the research group Studies of Popular Education, Movements and Social Organizations (GEEP/CNPq). E-mail: pschonardie@gmail.com.
} 


\section{Introdução}

As mais diversas experiências de vida e de trabalho, de práxis social, junto de movimentos e organizações, e na docência e na pesquisa, me permitem afirmar que a educação popular é uma concepção de educação. Ela "é uma prática educativa e uma proposta pedagógica que se situa dentro e diante dos conflitos históricos das sociedades latino-americanas" (STRECK et al., 2014, p. 21). Ela está enraizada na tessitura político-social brasileira e latino-americana, sobretudo nos espaços educativos cotidianos, mas também permeando os sistemas de ensino oficiais. Elaé construída histórica eorganicamente por sujeitos e coletivos, tendo raízes em tempos longínquos. Na condição de prática educativa e proposta pedagógica, indica sua possibilidade de permear também as vivências educativas futuras. Indica poder se constituir como um paradigma educativo latino-americano. Uma das questões de maior centralidade na educação popular é a sua perspectiva emancipatória. Sujeitos e coletivos se constroem protagonistas de sua história. O processo educativo, sob a perspectiva da educação popular acontece no cotidiano, de forma orgânica, como nos ensina Gramsci (2006). Não há um conceito absolutamente definido para ser "aplicado" nas práticas da educação popular. Mas há, evidentemente, fundamentos teórico-metodológicos, mas estes em constante reconstrução. Ela tem seu ponto de partida e também de chegada sempre na tessitura social. A educação popular se (re)constrói, assim, em movimento.

Desta perspectiva é possível inferir que a educação popular tem entre suas características "acompanhar o movimento da sociedade, buscando sempre novos espaços para a sua realização" (STRECK, 2013, p. 356). Paludo (2001) percebe assim a educação popular em busca de alternativas. Esses espaços ou alternativas se manifestam pelo contexto cotidiano, quase sempre adverso, vivido por indivíduos e coletivos, organizados em movimentos e organizações e mesmo em espaços de educação com reconhecimento oficial, como a escola e a Universidade. A educação popular está assim presente em um amplo espectro de processos educativos.

Mesmo um rápido olhar para a história latino-americana evidencia a histórica e constante presença de processos educativos populares como lugares de construção social coletiva (TORRES, 2008). Os processos educativos partem, desta forma, dos coletivos populares e de seus sujeitos, acompanhando as necessidades sociais concretas. Fica evidente "que os lugares da educação popular não são estáticos. [...] Ela tem também a capacidade de incorporar novos referenciais teóricos, sem perder o espírito que a alimenta" (STRECK; ESTEBAN, 2013, p. 8). Jara e Falkembach (2013) mostram que a educação popular requer referenciais teórico-metodológicos próprios. Mas ela é "visceralmente contrária à dogmatização, ela se reinventa em outros espaços quando instituições e grupos procuram domesticá-la" (STRECK; ESTEBAN, 2013, p. 8).

A atualidade brasileira apresenta um novo desafioà educação popular: seu reconhecimento como política pública, que tem seu ponto de partida no "Marco de Referência da Educação Popular para as Políticas Públicas" (SECRETARIAGERAL, 2014), doravante denominado "marco de referência". Com ele surgem estranhamentos, riscos, possibilidades, contradições e dúvidas. Políticas públicas partem de conceitos definidos, regulamentados e são implantadas para públicos específicos. A educação popular tem sim referenciais teórico-metodológicos próprios, que acompanham o movimento da sociedade, não são, portanto, tácitos. Pelas suas características e público, parece, no entanto, ser difícil fazer um enquadramento 
conceitual para balizar políticas públicas. Será que há riscos de dogmatização e domesticação?

Organizações e movimentos populares, contudo, sempre lutaram para eles próprios e as suas demandas serem reconhecidas e apoiadas pelo Estado. Estaria aqui uma das grandes possibilidades tanto de avanço das políticas públicas, quanto da ressignificação e reinvenção da educação popular? Teria ela agora possibilidades de penetrar "legalmente" nos sistemas de educação oficiais? Será que há riscos de se perder a "essência" popular ou será que esta que adentrará em novos espaços? É importante lembrar que existem experiências de educadores e de educadoras populares que se utilizam de práticas teórico-metodológicas da educação popular para humanizar espaços educativos. A educação do campo, a pedagogia social e a educação em saúde podem também ser espaços de educação popular, pois têm em comum muitos fundamentos teóricometodológicos. Tanto a educação do campo, quanto a pedagogia social e a educação em saúde, possuem, de uma ou outra forma, denominações formais como política pública. Há, assim, precedentes históricos paralelos à educação popular como política pública. As mesmas questões, desafios, dúvidas e estranhamentos que agora desafiam a educação popular também são comuns. Olhar para esses precedentes traz consigo um potencial de análise e entendimento frente aos novos desafios e caminhos da educação popular como política pública.

Para avançar no debate, gerado pelo status da educação popular como política pública, torna-se imprescindível primeiro voltar ao conceito histórico da educação popular. Na sequência, a retomada do processo de debate e da incipiente legislação relativa à educação popular como política pública. Com a teoria e a determinação legal presentes, se torna necessário olhar paralelamente para campos educativos da educação popular, como a educação do campo, a pedagogia social e a educação em saúde que já têm histórico de política pública. A partir dessas análises, considero possível avançar no atual desafio da educação popular como um caminho que aponta estranhamentos, contradições, riscos, dúvidas e possibilidades.

\section{Bases histórico-conceituais}

A educação popular se constrói historicamente de forma orgânica na conjuntura social e política. Sua origem e teorização são basicamente latino-americanas. Ou seja, no cotidiano de históricas desigualdades da América Latina, é que sujeitos e coletivos procuraram e continuam procurando por si próprios elaborar experiências educativas em que participam ativamente se (re)significando como sujeitos de sua história. Tanto Weinberg (1984) quanto Streck et al. (2014) compreendem que a história da educação popular tem seu ponto de partida no encontro violento entre colonizador e colonizado, e de um projeto de modernidade inconcluso, e por isso se refundamenta, ressignifica, reinventa e refunda nas práticas do cotidiano. A educação popular se dá, assim, na "aposta e possibilidade, entre a paciência e a impaciência" (STRECK, 2010b, p. 309), o que para Freire (1982, p. 7) se apresenta em forma de um processo dialético. Para Puiggrós (2014, p. 103), a história da educação popular tem um significativo peso na "recuperação da dignidade política e social", o que para Streck et al. (2014, p. 34) é complementado na construção de uma educação libertadora em nosso continente.

Constatar a origem e o desenvolvimento da educação popular na parte latina da América não significa negar que também haja experiências que se valham de práticas teóricometodológicas semelhantes e que se tenham desenvolvido paralelamente, como é o caso da pedagogia social na Alemanha. A educação popular, entretanto, representa a construção de um pensamento pedagógico latino-americano 
(STRECK, 2010a, p. 331; MEJÍA, 2013, p. 369). E esta constatação ganha em reconhecimento, por exemplo, quando Fichtner (2013, p. 349) afirma que a pedagogia social europeia tem a aprender com a educação popular. É importante, contudo, ressaltar aqui que não é objetivo alçar as experiências de educação popular acima de outras práticas educativas - seria um equívoco histórico fazê-lo -, mas enfatizar que ela tem a contribuir, e contribui efetivamente a partir do contexto em que se desenvolve, tendo seu maior potencial em sua característica de construção da autonomia de sujeitos e coletivos no processo educativo. E nesse movimento, que os seres humanos, em um caminho de humanização, não apenas se adaptam à natureza, mas a transformam, transformando-se a si mesmos (MARX, 2008, p. 192), e esta transformação, com sentido de humanização acontece em um processo de aprendizagem orgânico, o que já se pode denominar de educação popular.

Com base nos estudos de Marco Raul Mejía e Myriam Awad (2003) é possível perceber a educação popular em dois períodos distintos. Esses autores relacionam o ponto de partida aos processos de independência política latino-americanos. Por isso, Puiggrós (2014) afirma que a educação popular, como proposta de educação, inicia-se com Simón Rodríguez (1769-1854). O primeiro período apontado por Mejía e Awad (2003), se inicia no século 18, seguindo até a primeira metade do século 20. Certamente a participação de setores e ideias populares nos processos de independência política dos países latinos do continente contribuiu organicamente para os primórdios da educação popular. É possível perceber, nesse entrelaçamento da educação popular com as lutas pela independência, sua característica em acompanhar os movimentos da sociedade.

Em reflexão bastante atual, Mejía (2013, p. 370) nos lembra mais uma vez que Simón Rodríguez e José Martí estão no primeiro tronco de pensadores que, pela educação popular, procuram dar respostas às crises de contextos específicos, como foi nas lutas pela independência ou é na premente conjuntura atual. Buscando primórdios da educação popular na realidade do século 18, não se exclui que tenha havido experiências em períodos anteriores, por exemplo, entre as complexas sociedades Incas, Maias e Astecas, e mesmo entre os Guaranis das Reduções. Buscar a tessitura nestas e outras sociedades mais antigas constitui ainda um campo aberto para a pesquisa.

A fundamentação do primeiro período da educação popular pode ser buscada no pensamento de Simón Rodríguez (1979). Ele apresenta três características básicas, que denomina uma forma de educação popular entrelaçada em seu tempo. Para Rodríguez (1979), é pela educação que: a) nos tornamos "americanos" e não europeus, ou seja, inventores e não repetidores. Está aqui um dos fundamentos do protagonismo dos participantes dos processos educativos, em perspectiva de construir uma cultura latino-americana; b) nos educamos para não sermos mais servos. O que pode significar a libertação das amarras coloniais, inclusive a libertação cultural; e, c) para aprender um ofício para ganhar a vida por conta própria. Ou seja, construir autonomia como sujeitos de sua história pelo trabalho.

O segundo período começa para Mejía e Awad (2003) em meados do século 20, seguindo na atualidade. É possível afirmar que, nesse período, a educação popular profundamente imbricada no acompanhar do movimento da sociedade, incorporou e continua incorporando novos referenciais e estes a partir das experiências concretas protagonizadas na base social. Nessas últimas décadas é que se consolida um pensamento pedagógico latino-americano, qual seja, a educação popular. Esse período coincide com o desenvolvimento do pensamento pedagógico de Paulo Freire (STRECK, 2010a, p. 331). Freire contribui significativamente para revolucionar a teoria e a prática da 
educação popular e, consequentemente, de todo o contexto educacional. Nesse sentido "a pedagogia do oprimido se alonga em pedagogia da pergunta, pedagogia da esperança, pedagogia da autonomia, pedagogia da indignação e outras mais" (STRECK, 2010b, p. 301).

Admitindo que a educação popular possui referenciais teórico-metodológicos próprios, é contundente indagar: Que referenciais são esses? Para aprofundar o questionamento, é possível ir além com a pergunta feita por Brandão (2006): "O que é a educação popular?". Acompanhando Torres (2008, p. 13), é importante ter presente, que não existe uma única e/ou absoluta compreensão ou definição de educação popular. Mas ela parte primeiro do reconhecimento da existência e depois do protagonismo histórico dos sujeitos e dos coletivos envolvidos. Neste reconhecimento parece estar situada a vocação da educação como forma de resistência (BRANDÃO, 2013, p. 12).

Da mesma forma que Torres (2008; 2013), outros autores que baseiam suas práticas na educação popular, tais como Brandão (2006), Mejía (2013), Paludo (2008), concordam que há uma profunda heterogeneidade nas práticas, nos atores e nos referenciais teóricometodológicos, mas também entendem que é possível e necessário identificar um conjunto de ideias centrais comuns, que dão forma e identidade a ela como uma concepção autônoma de educação.

A numerosa e histórica existência de oprimidos e sua luta para sair da opressão (FREIRE, 1987) fazem com que a educação popular emerja "como um movimento de trabalho político com as classes populares através da educação" (BRANDÃO, 2006, p. 75). A concepção pedagógica da educação popular está assim profundamente enraizada na sua "alta sensibilidade aos contextos políticos, sociais e culturais" (TORRES, 2013, p. 19), tendo uma "intencionalidade política emancipadora"
(TORRES, 2008, p. 13). Concretamente é "um processo de libertação via conscientização e luta política" (STRECK et al., 2014, p. 31). Desse ponto de partida se pode começar a construir um núcleo da educação popular

a partir de uma crítica indignada da ordem social dominante e a partir da identificação com visões de futuro alternativas, [...] [buscando] contribuir para a constituição de diversos setores subalternos como sujeitos de transformação, incidindo em diferentes âmbitos de sua subjetividade, mediante estratégias pedagógicas dialogais, problematizadoras, criativas e participativas. (TORRES, 2013, p. 19).

A educação popular possui uma estreita ligação com as margens (EGGERT, 2003), abrindo possibilidades de subjetivação naqueles espaços e por meio daquelas pessoas comumente excluídas dos sistemas educativos oficiais constituídos, ou seja, dos oprimidos em busca de sua libertação. A educação popular constitui, assim, espaços e territórios de resistência (STRECK, 2010b). São os "outros sujeitos" que constroem "outras pedagogias" (ARROYO, 2014). Ela é assim uma forma pedagógicosocial provinda dos contextos históricos e culturais de luta social. Nesses contextos que se constrói o núcleo comum da educação popular, entendido por Paludo (2008) a partir de quatro elementos fundamentais: a estreita relação entre o político e o pedagógico, o que indica objetivamente que a educação não é neutra; a centralidade dos participantes dos processos educativos populares como sujeitos históricos; a perspectiva emancipadora que objetiva a transformação social; a compreensão de que o conhecimento é socialmente produzido.

Para Mejía (2013, p. 372), a educação popular se constitui como uma proposta para a sociedade a partir de uma longa experiência acumulada, que o sul geográfico apresenta para a humanidade. Ele afirma enfaticamente que na 
educação popular "se parte de que todos los humanos tienen un saber derivado del mundo que habitan y las prácticas que desarrollan en lo cotidiano de sus vidas" (MEJÍA, 2013, p. 373).

A educação popular é assim "uma prática educativa que se propõe a ser diferenciada, isto é, compromissada com os interesses e a emancipação das classes subalternas" (PALUDO, 2001, p. 82). Por ela se buscam a constituição de sujeitos populares "capazes de serem os construtores de sua própria história de libertação" (PALUDO, 2001, p. 99). A autonomia de sujeitos e de seu grupo social passa a ter papel central. Transparece a pedagogia da autonomia (FREIRE, 2002), e isto não vem ao acaso, pois os autores e as concepções acima apresentados se baseiam na experiência prática e na consequente teorização revolucionária para a qual também Paulo Freire contribui a partir de meados do século 20.

A práxis, ou seja, a ação, a reflexão e a nova ação são características do humano. "Atuando, transforma; transformando, cria uma realidade, que, por sua vez, 'envolvendo-o', condiciona sua forma de atuar" (FREIRE, 1992, p. 28). Os humanos se reconhecem assim como inacabados (FREIRE, 1987). Freire sempre esteve convencido de que qualquer esforço da educação popular precisaria ter um objetivo fundamental, o "da problematização do homem-mundo ou do homem (sic) em suas relações com o mundo e com os homens (sic), possibilitar que estes aprofundem sua tomada de consciência da realidade na qual e com a qual estão" (FREIRE, 1992, p. 33).

As bases teórico-metodológicas da educação popular até aqui sucintamente apresentadas contribuíram para o reconhecimento que os humanos fizeram da sua condição de sujeitos históricos transformadores, transformando seu mundo pela práxis social contestatória em um lugar equitativamente mais justo. E esta luta da educação popular foi muitas vezes de contestação perante a educação formal (STRECK, 2006), ou seja, pelo que denomino aqui de contestação aos sistemas oficiais de educação constituídos. No momento contemporâneo com o reconhecimento da educação popular como política pública, ela passa a ter também certo status de formalização, o que provoca estranhamentos e questões abertas.

\section{0 marco de referência da educação popular para as políticas públicas}

Em maio de 2014, o governo brasileiro publicou Portaria no Diário Oficial da União, com o "Marco de Referência da Educação Popular para as Políticas Públicas", que representa a formalização da educação popular como política pública. A educação popular passa a ter o reconhecimento formal, oficial, o que é contraditório ao seu movimento histórico, ou seja, ela tem, conforme Streck (2006), histórico de contestação à educação formal, ou seja, aos sistemas de ensino oficialmente constituídos e reconhecidos.

O marco de referência, da mesma forma que a educação popular, é fruto de seu contexto social, ou seja, foi produzido pela conjuntura da existência de um governo democrático e popular. Com a eleição democrática de governos com tendências populares na América Latina, o que Paludo (2001) denominou de ascensão do campo democrático e popular, entre os quais o brasileiro, chegaram ideias e pessoas ligadas à educação popular às gestões nacionais. À educação popular se apresentaram assim novos desafios e campos de atuação, com a possibilidade de penetrar formalmente em processos educativos rigidamente controlados. O marco de referência "reflete um novo momento na valorização destas práticas que acontecem dentro e fora do Governo Federal" (CARVALHO, 2014, não paginado).

A elaboração do marco legal é 
resultado de um amplo processo de debates, diálogos e reflexões, a partir de diferentes práticas, do Governo Federal, de movimentos sociais, de universidades e de educadores populares e da educação formal do Brasil, desenvolvido por meio de reuniões, seminários e articulações entre 2011 a 2014, coordenado pela Secretaria Geral da Presidência da República [...]. Também incorporou diferentes contribuições, por meio de duas consultas públicas no portal www. participa.br. (SECRETARIA-GERAL, 2014³).

Entendo que somente foi possível elaborar o marco de referência por ter havido formulação histórica e teórico-metodológica anterior a sua curta fase de debate. Isto é indiretamente reconhecido no marco de referência, quando traz bases históricas da educação popular no Brasil (SECRETARIA-GERAL, 2014).

De acordo com o marco de referência, já no ano de 2006 a Rede de Educação Cidadã (Recid), que congrega governo e organizações da sociedade civil, pautou a necessidade da educação popular como política pública, o que tomou forma no Fórum Social Mundial de Belém, no ano de 2009, sendo construída a partir daí uma estratégia de ação que culminou com o processo oficial de elaboração do documento base para o marco de referência.

O contexto de elaboração do marco de referência é percebido como um momento em que as condições econômicas e sociais dos brasileiros avançaram muito, surgindo uma nova classe média trabalhadora, que se constituiu consumista e individualista (SECRETARIAGERAL, 2014). Transparece assim a condição de "alienação" dos trabalhadores (MARX, 2008), agora supostamente incluídos no sistema capitalista e sem se perceber como protagonistas de sua história. Neste sentido, os processos de educação popular são vistos, com o marco de referência inclusive pelo Estado, como uma das formas para que os sujeitos reajam, construindo consciência sobre sua real situação.

Desta perspectiva se inserem os objetivos do marco de referência, estando em seu cerne à promoção de "um campo comum de reflexão e orientação de práticas coerentes com a perspectiva metodológica proposta pela educação" (SECRETARIA-GERAL, 2014). Mas é importante saber que o marco de referência foi criado principalmente para "apoiar os diferentes setores do governo em suas ações educativas e formativas [...] [para] alcançar o máximo de resultados" (SECRETARIA-GERAL, 2014). De imediato é necessário refutar essa busca máxima de resultado, sobretudo quando a perspectiva é mediroalcance de políticas públicas, que, mesmo em um governo inserido no campo democrático e popular, segue "receitas" neoliberais, tanto na perspectiva micro quanto macro. Do ponto de vista teórico, o marco de referência possui sua solidez, estando embasado basicamente em Paulo Freire, apresentando a educação popular como um edifício instituído, o que é questionável. Não faz referência à pluralidade de experiências históricas (tais como aquelas vividas nos anos 1950 e 1960 no nordeste brasileiro), nem às múltiplas interpretações teóricas. Reconhece, no entanto, que a educação popular articula diferentes saberes e práticas, e tem compromisso com o diálogo e com o protagonismo das classes populares nas transformações sociais (SECRETARIAGERAL, 2014). Epistemologicamente se fundamenta em Paulo Freire, destacando o diálogo, a amorosidade, a conscientização, a transformação da realidade e do mundo, o ponto de partida na realidade concreta, a construção do conhecimento pela pesquisa participante e a sistematização de experiências como bases da educação popular (SECRETARIA-GERAL, 2014). Com essa concepção propõe que seu percurso

3. O marco de referência foi publicado em um documento pela Secretaria-Geral da Presidência da República, sem estar paginado. Desta forma é identificado nas citações como "Secretaria-Geral", seguido apenas do ano da publicação. Pode ser acessado na página da Secretaria-Geral da Presidência da República. 
metodológico parta da realidade social, devendo esta ser problematizada, para posteriormente elaborar plano de ação, que, por sua vez, servirá para reinventar de forma consciente a realidade da qual partiram (SECRETARIA-GERAL, 2014).

Qualquer política pública possui um conjunto de regras para serem seguidas. Nessas regras é que há riscos de engessamento. No marco de referência, elas são dadas por princípios e, sobretudo, por diretrizes "para as ações de educação popular nas políticas públicas" (SECRETARIA-GERAL, 2014). Em grande parte, tanto os princípios quanto as diretrizes são extraídas do movimento histórico, do conceito e da práxis da educação popular. Os princípios se referem basicamente à emancipação popular, participação, equidade, solidariedade, criticidade, justiça. Já com as diretrizes surgem as contradições. No marco de referência é apresentado um conjunto de trinta e três diretrizes, possíveis de serem divididas em dois blocos. Em um deles estão aquelas diretamente relacionadas à história e aos preceitos epistemológicos da educação popular, podendo-se inferir que a partir delas haverá um fortalecimento da concepção pedagógica popular de educação. O outro bloco é aquele relacionado aos interesses e às formas de funcionamento do Estado. Desse bloco, destaco aquelas diretrizes que percebo poderem ser caras à autonomia da educação popular: o fortalecimento do processo educativo

considerando a importância da organização econômica da sociedade como dimensão fundamental para a emancipação popular; promover processos educativos na perspectiva da Educação Popular para ampliar o acesso a políticas e aos recursos públicos; consolidar a criação de indicadores para avaliação e monitoramento dos processos e resultados de políticas públicas a partir do referencial da Educação Popular. (SECRETARIA-GERAL, 2014).

O marco de referência é encerrado afirmando que a educação popular "é uma ferramenta necessária para que seus princípios como o da amorosidade, do respeito aos diferentes saberes sejam consolidados em espaços como de escolas públicas, dos hospitais, universidades, faculdades entre outros" (SECRETARIA-GERAL, 2014). O grande campo das práticas da educação popular é visto como uma contribuição à pedagogia, como consolidação de um processo pedagógico popular, com potencial de penetrar nos espaços pedagógicos oficialmente reconhecidos e também nas políticas públicas de forma ampla.

\section{Paralelos com a educação do campo, a pedagogía social e a educação em saúde}

Diversos são os espaços e coletivos em que os processos de educação popular se manifestam. E em muitos desses espaços foram conquistadas políticas públicas específicas, as quais também se apresentam contraditórias, ou seja, fomentam, por um lado, à prática histórica popular e, por outro, imprimem anseios específicos provindos do Estado. Olhar criticamente para esses espaços traz consigo um potencial muito grande de compreensão das possíveis veredas que a educação popular, em sua agora relação direta com as políticas públicas, está ambientando.

A educação do campo, a pedagogia social e a educação em saúde são casos emblemáticos, para os quais já há histórico de políticas públicas, tornando-se importantes para o debate aqui proposto. Não é pretensão, contudo, conceituar a educação do campo, a pedagogia social e a educação em saúde, muito menos esgotar a relação de cada uma destas categorias com a questão pública. Também não é pretensão realizar uma comparação entre as características e diferenças (mesmo que algumas características e diferenças sejam abordadas para dar sentido à proposta aqui em desenvolvimento) desses campos específicos e a educação popular. É objetivo pautar alguns 
elementos que possam elucidar um potencial de análise e entendimento frente aos novos desafios e estranhamentos e, ao mesmo tempo, caminhos da educação popular como política pública.

Os camponeses são um desses coletivos ou categorias sociais que lutam por processos educativospopularesquegarantamamanutenção e reprodução da condição camponesa, em um modo de produção camponês. A condição camponesa se dá por meio de processos educativos que, na atual conjuntura social, se apresentam sob a forma da educação do campo, que também tem em seu cerne o protagonismo social dos camponeses, ou seja, eles próprios, marcados pela sua condição camponesa e pelo modo de produção camponês se assumem como sujeitos conscientes de sua história. Antônio Munarim (2014) situa a educação do campo como um movimento por políticas públicas. Para o autor os intelectuais da educação do campo são orientados pela tríade "Campo-Educação-Políticas Públicas" (MUNARIM, 2014, p. 140). Educação do campo é um conceito novo e a própria expressão "educação do campo", como nos mostra Fernandes (2005, p. 1) é nova; surgiu no bojo da conjuntura em que a educação popular ganhou importância. Ao mesmo tempo os camponeses, suas organizações e seus intelectuais orgânicos, em um esforço organizacional e de pressão construíram um movimento social por políticas públicas (MUNARIM, 2014). A educação do campo, contou, assim, desde seu início, com programas governamentais específicos, dentre eles o Programa Nacional de Educação na Reforma Agrária (Pronera); o Programa de Apoio à Formação Superior em Licenciatura em Educação do Campo (Procampo), pois logo foi constatada a necessidade da formação de professores para a educação do campo, sendo então instituídas licenciaturas específicas (MUNARIM, 2014); e a constituição do Observatório da Educação do Campo com recursos da Capes.
A partir desta conjuntura três questões merecem destaque. A primeira, com a construção de políticas públicas específicas para a educação do campo houve ampliação do debate acerca do tema, seja entre camponeses/as, pesquisadores/ as, educadores/as e lideranças sindicais, o que resultou em um avanço significativo na produção epistemológica. A educação do campo foi situada como tema nacional e pelo Brasil como referência no contexto internacional. Certamente um ganho muito importante para a condição camponesa, para o campesinato.

A segunda questão parece apresentar um limitador para a educação do campo, apontando como alerta para a educação popular. Todo o desenvolvimento de programas específicos, de eventos ligados ao tema, de cursos etc. se deu pela disponibilidade de recursos públicos. Essa situação fez com que houvesse uma expansão que deixou de lado a base epistemológica popular da educação do campo. Multiplicaramse, por exemplo, licenciaturas em educação do campo, mas essas inseridas mais uma vez na perspectiva da modernização capitalista da agricultura, ou seja, fazer o camponês produzir para vender seus produtos para a nova classe média individualista (SECRETARIAGERAL, 2014), o que já não tem mais nada a ver com a condição camponesa, logo, com a essência da educação popular do campo.

A terceira questão emerge da própria alienação consumista já apontada pelo marco de referência (SECRETARIA-GERAL, 2014) e que se aplica também aos sujeitos habitantes do campo e teoricamente possíveis de enquadrar na categoria social do campesinato. Na esteira das políticas desenvolvidas para o campo, e erroneamente usando as justificativas da necessidade da educação do campo, foi criado, por setores conservadores, o Pronatec-Campo. A partir do estudo de Lottermann (2017) é possível afirmar que o Pronatec-Campo é uma estratégia do agronegócio e que com ele muitas das conquistas dos últimos anos da educação do 
campo passam a ser corroídas. Isso é possível, pois os camponeses - alienados pela sua inserção na sociedade consumista e acreditando na já consolidada relação do desenvolvimento da educação do campo com aportes do Estado, pela tríade campo-educação-políticas públicas -, aceitam passivamente o Pronatec-Campo sem se dar conta da contradição (MUNARIM, 2014). Esse é um alerta contundente para o aprofundamento da tessitura da educação popular com as políticas públicas.

Emblemática também é a pedagogia social. Pessoalmente tenho dúvidas em nomeála como campo da educação popular, pois a categoria da conscientização, que é central na educação popular, não está presente na pedagogia social. Na Alemanha, por exemplo, a pedagogia social "procura responder a questões a respeito do processo de integração do indivíduo à sociedade" (FICHTNER, 2013, p. 349). Essa integração se dá no modo de produção capitalista. É importante lembrar que os Estados Nacionais estão organizados para o bom funcionamento do modo de produção capitalista e, dessa forma, suas políticas servem para integrar pessoas ao sistema, ou seja, ao capitalismo. Talvez por isso a pedagogia social seja reconhecida pelo Estado, a ponto de, no Brasil, o educador social ter sua profissão regulamentada pelo Projeto de Lei 5346/09 (BRASIL, 2009). Há, entretanto, um esforço entre educadores que se ocupam com a pedagogia social (SILVA; MACHADO, 2013; FICHTNER, 2013) em mostrar que ela compartilha com a educação popular concepções teóricas, metodológicas e também o contexto empírico, tendo assim os mesmos públicos. Logo esses autores entendem que ela é uma forma de educação popular. Na prática, a pedagogia social está, por exemplo, em projetos de inclusão social de desempregados, portadores de necessidades especiais, adolescentes em situação de risco e em sistema prisional, moradores de rua. A inclusão destes para o "bom funcionamento" da sociedade capitalista é interesse do Estado e, é feita a partir de recursos disponibilizados pela "máquina pública".

As questões que emergem são mais uma vez a dependência de recursos estatais e, por outro lado, a intervenção a partir do que o Estado quer, ou seja, sua integração ao sistema vigente, e não o protagonismo consciente de libertação dos sujeitos envolvidos.

Já a educação popular em saúde traz uma perspectiva completamente diferente de introdução da educação popular como política pública. As políticas públicas na área da saúde possuem um histórico de décadas e nelas é que a educação popular procura penetrar como diretriz teórica e metodológica. Hoje, há um incentivo para que a educação popular "se torne uma estratégia prioritária de humanização do SUS $^{4}$ e de adequação de suas práticas técnicas à lógica de vida da população por meio da valorização de formas participativas de relação entre os serviços de saúde e os usuários" (VASCONCELOS, 2013, p. 122).

$\mathrm{Na}$ área da medicina, por exemplo, existe um conjunto muito grande de conhecimento científico, disponibilizado pelos sistemas de saúde estatais à população. Algumas pessoas, contudo, possuem uma resistência à aplicação desses conhecimentos sobre seus corpos. Elas chegam aos serviços de saúde com uma forma própria, "popular", de ver o mundo. Em se criando um ambiente educativo popular nos espaços de saúde oficiais, torna-se possível fazer a mediação entre a técnica e o conhecimento popular. Tschajanow (1924, p. 32-33) nos ensina a não lutar contra o espírito popular, mas a trabalhar a partir da forma popular de se viver. Para concretizar isso, os profissionais da saúde precisam estar preparados também para serem educadores populares. Aqui está uma das potencialidades mais importantes da educação popular como política pública: penetrar nos

4. Sistema Único de Saúde. 
sistemas formais de educação, preparando seus educandos para serem também educadores populares.

\section{Algumas considerações: ponderando estranhamentos e possibilidades}

A educação popular possui uma história a partir da América Latina e uma construção teórico-metodológica consistente e consolidada proveniente das experiências e lutas sociais de indivíduos e coletivos em sua base social. Mas não há, para ela, uma definição absoluta e muito menos definitiva. Pela sua essência, ela vai se reconstruindo na tessitura social, com o protagonismo histórico e social de sua base orgânica. E, como provinda da conjuntura social, está aberta, seja em sua forma teóricometodológica, seja a novos grupos sociais, e, ao mesmo tempo sujeita a confrontos com outros interesses da sociedade bem como com o Estado.

É importante voltar à questão de a educação popular ter-se desenvolvido às margens das determinações educativas e sociais do Estado e muitas vezes em confronto direto com ele. Ao mesmo tempo, pode-seafirmarquea educação popular sempre teve uma relação com o Estado, mesmo não havendo historicamente uma política pública propriamente dita para ela. Já em seu primeiro período, seguindo o pensamento de Puiggrós (2005) e Mejía (2013), as formulações de Simón Rodríguez e José Martí foram adaptadas por Andrés Bello e Domingo Faustino Sarmiento na construção de um sistema público de ensino que viesse a ser popular. Mas logo, na maioria dos casos, o ideário popular foi abandonado com a quase transposição de um sistema de ensino europeu tacitamente definido. Posteriormente, já no limiar de seu segundo período, a constituição de universidades públicas também foi balizada pelo ideário de terem sua base nos preceitos teórico-metodológicos da educação popular. O sistema, entretanto, também as absorveu.
No tempo presente, mais uma vez há tentativas novas na constituição de universidades populares. Na região sul do Brasil, por exemplo, uma nova universidade chegou a ser declarada universidade popular, e sem dúvida, elementos da educação popular estão em sua base de constituição, mas ela, para ser universidade no sistema universitário brasileiro, que é minuciosamente controlado por "agências" estatais, já foi absorvida pelas regras vigentes, fazendo com que a concepção e a prática da educação popular estejam em segundo plano. Inclusive as experiências de educação popular protagonizadas por Paulo Freire tinham de uma ou outra forma, tessitura com o Estado.

É perceptível, assim, que em diversos períodos históricos, as políticas estatais tangenciaram a educação popular e por vezes tentaram se basear nela. A educação popular, nesses momentos, teve a resiliência de se reconstruir, de avançar em seus caminhos, sem deixar suas características centrais de lado. $\mathrm{Na}$ atualidade, entretanto, a relação e ao mesmo tempo o desafio junto ao Estado se dá com maior profundidade. É fato que pela primeira vez na história há um conjunto de regras estatais específicas para a educação popular. Há agora um marco de referência da educação popular para as políticas públicas. Princípios e diretrizes são apontadas pelo Estado e, mesmo que esses princípios e essas diretrizes sejam originários da conjuntura social e da educação popular propriamente dita, passam a se apresentar como um conjunto de regras, que sob o ponto de vista das políticas públicas se institucionalizam, perdendo força de movimento.

Cabe voltar à pergunta que questiona se há uma tentativa de domesticar e institucionalizar a educação popular. Ao que parece não se trata disso, visto que o atual contexto é fruto da luta social do grande campo pedagógico da educação popular para ser reconhecido como política pública. Mas sempre há esse risco, pois agora há orientações definidas de políticas para 
a educação popular. Com base na história, entretanto, ela sempre foi autônoma, sabendo acompanhar o movimento da sociedade, com a sensibilidade de buscar novos espaços e ao mesmo tempo se libertar das tentativas de institucionalizá-la. Para que uma política pública não se "cristalize", tem de haver um esforço para que ela se mantenha na fronteira entre "ser movimento" e "ser instituição".

É natural que assim como aconteceu com a educação do campo, a educação popular, agora como política pública, já está tendo uma visibilidade muito maior. O tema está ganhando espaço institucional o que traz consigo obviamente riscos e potencialidades. Um desses riscos provém da possibilidade de dotações orçamentárias específicas para projetos da educação popular. Não se trata aqui de ser contra a alocação de recursos públicos para a educação popular. O problema está em se colocar a centralidade na viabilidade financeira de projetos. Paralelamente é interessante olhar para a educação do campo: quando da disponibilidade de recursos, agregou muitos interessados em implantar projetos, e esses com pouca ou nenhuma noção dos campos teórico-metodológico e prático. Quanto à educação popular, não se pode esquecer que com o marco de referência, além de sinalizar com políticas financeiras, propõe indicadores de controle, avaliação, monitoramento e maximização de resultados, baseados na centralidade da dimensão econômica. Aqui se está muito próximo da pedagogia social, ou seja, a autonomia dos sujeitos e coletivos passa a ser substituída pela contraditória inclusão no modo de produção capitalista. Seria uma forma de domesticar a educação popular. Já as possibilidades que se abrem para a educação popular como política pública começaram pela participação da sociedade e de suas organizações na construção do marco de referência e podem se ampliar no indicativo da continuidade participativa. Há, portanto, fidelidade às concepções teórico-metodológicas histórica e organicamente construídas. E mais profundamente, agora as políticas públicas, para além somente daquelas específicas do campo da educação, estão orientadas a integrarem a perspectiva da educação popular. Por isso também a necessidade de se partir de uma sólida teoria com proposições para a política. Houve uma conjuntura favorável: foi criado um lugar no Estado para cuidar da educação popular que chegou a demonstrar uma vontade política de viabilizá-la em projetos sociais, culturais e econômicos; há experiências paralelas de outras áreas. Dessa realidade pode-se questionar se há possibilidade concreta de humanizar a ação estatal, percebendo-se logo que há indícios dessa humanização. Um exemplo clássico é a forma como educadores e educadoras populares têm penetrado com suas práticas no campo da saúde.

Por outro lado, tudo o que a educação popular historicamente construiu pelos seus sujeitos e coletivos e à margem das formalidades não tem por que não continuar, e certamente seguirá reconceituando a educação popular desde as suas bases, tendo mais do que nunca a tarefa de fazer valer organicamente a sua capacidade de não perder o espírito que a alimenta. E a importância dos sujeitos e coletivos em sua base, sem depender de políticas estatais, tem aumentado nos últimos meses.

Conjunturalmente é preciso ter presente as conturbadas e recentes mudanças nos cenários políticos latino-americanos. No Brasil é fato que o marco de referência e suas recomendações existem. A troca brusca de governo eleito e alinhado ao campo democrático e popular por governo conservador, pelo processo de impeachment, com características efetivas de golpe, provocou mudanças significativas para as possibilidades de a educação popular penetrar as políticas públicas. O tempo atual é assim muito distinto daquele que possibilitou a um governo de centro-esquerda (do campo democrático e popular) estabelecer a educação 
popular como um marco de referência para as políticas públicas. A ruptura causada pela mudança governamental foi muito grande. O "novo" governo simplesmente extinguiu o Departamento de Educação Popular e Mobilização Cidadã, então vinculadoà Secretaria Nacional de Articulação Social e à Secretaria da Presidência da República, acabando com o setor responsável por acompanhar a implementação do marco de referência. As políticas públicas brasileiras seguem agora orientações políticoideológicas completamente antagônicas à educação popular, trilhando um caminho "neo"-neoliberal, neoconservador e de restauração absoluta da hegemonia capitalista. Não é possível e nem objetivo de minha reflexão, no entanto, avaliar profundamente essas mudanças. A nova configuração do Estado e novas tessituras possíveis com a educação popular demandam, assim, novas pesquisas, que precisam acompanhar o movimento da história e da sociedade. A potencialidade maior, agora juridicamente embasada com um marco de referência, está no fato de a educação popular possuir o respaldo de poder penetrar organicamente em todos os espaços formativos. A mudança na conjuntura política não acaba com a possibilidade de a educação popular penetrar as políticas públicas. O marco de referência continua existente. Dois exemplos: o primeiro, as políticas da área da saúde têm uma longa história e desde alguns anos são perpassadas por algumas práticas de educação em saúde baseadas na educação popular, podendo ser nomeadas assim de "educação popular em saúde". O segundo: o sistema educativo oficial também é histórico, centenário, e é sabido que muitos educadores também já têm um histórico de introdução de fundamentos teórico-metodológicos e epistemológicos da educação popular em suas práticas nos sistemas educativos oficiais, seja na escola ou na universidade. Mesmo na atual conjuntura adversa é concreta a possibilidade para que a perspectiva pedagógica latino-americana da educação popular se generalize também nos sistemas educativos oficiais, isto sem que se perca o espírito orgânico que alimenta a educação popular. Aqui está não só a potencialidade, mas o grande desafio que se põe às educadoras, aos educadores e à própria educação popular.

\section{Referências}

ARROYO, M. G. Outros sujeitos, outras pedagogias. Petrópolis: Vozes, 2014. 336 p.

BRANDÃO, C. R. O que é a educação popular? São Paulo: Brasiliense, 2006. 61 p.

. Prefácio. Cinquenta e um anos depois. In: STRECK, D.; ESTEBAN, M. T. (Org.). Educação popular: lugar de construção social coletiva. Petrópolis: Vozes, 2013. p. 9-14.

BRASIL. Projeto de Lei 5346/2009. Dispõe sobre a criação da profissão de educador e educadora social e dá outras providências. Brasília: Câmara dos Deputados, 2009. Disponível em: <http:// www.lexml.gov.br/urn/urn:lex:br:camara.deputados:projeto.lei;pl:2009-06-03;5346>. Acesso em 15 nov. 2017.

CARVAlHO, G. Apresentação. In: SECRETARIA-GERAL da Presidência da República. Marco de Referência da Educação Popular para as Políticas Públicas. Brasília: Secretaria-Geral, 2014. Disponível em: <http://conae2014.mec.gov.br/images/pdf/MarcodeReferencia.pdf>. Acesso em: 12 nov. 2017. 
EGGERT. E. Educação popular e teologia das margens. São Leopoldo: Sinodal, 2003. 180 p. (Série Teses e Dissertações, v. 21).

FERNANDES, B. M. Os campos da pesquisa em educação do campo: espaço e território como categorias essenciais. In: MOLINA, M. C. (Org.). Educação do campo e pesquisa: questões para reflexão. Brasília: Ministério do Desenvolvimento Agrário, 2006. p. 27-40.

FICHTNER, B. Educação popular: uma visão europeia. In: STRECK, D.; ESTEBAN, M. T. (Org.). Educação popular: lugar de construção social coletiva. Petrópolis: Vozes, 2013. p. 348-355.

FREIRE, P. Extensão ou comunicação? Rio de Janeiro: Paz e Terra, 1992. 128 p.

2002. 144 p.

Pedagogia da autonomia. Saberes necessários à prática educativa. São Paulo: Paz e Terra, Pedagogia do oprimido. Rio de Janeiro: Paz e Terra, 1987. 184 p.

. Virtudes do educador. São Paulo: Vereda, 1982.

GRAMSCI, A. Cadernos do cárcere. v. 2. Rio de Janeiro: Civilização Brasileira, 2006.

JARA, O.; FALKEMBACH, E. M. F. Educação popular e sistematização de experiências. In: STRECK, D.; ESTEBAN, M. T. (Org.). Educação popular: lugar de construção social coletiva. Petrópolis: Vozes, 2013. p. 151-166.

LOTTERMANN, O. Perspectivas da educação profissional do campo sob as mediações entre a sociedade voltada para o consumo e um projeto cooperativo e solidário. 2017, 137 f. Tese (Doutorado em Educação nas Ciências) - Universidade Regional do Noroeste do Estado do Rio Grande do Sul, ljuí, 2017.

MARX, K. Das Kapital. Berlin: Dietz, 2008.

MEJÍA, M. R.; AWAD, M. I. Educación popular hoy: en tiempos de globalización. Bogotá: Aurora, 2003. 160 p. (Coleccion Educacion Popular).

MEJÍA, M. R. Posfácio. La educación popular. Una construcción colectiva desde el sur y desde abajo. In: STRECK, D.; ESTEBAN, M. T. (Org.). Educação popular: lugar de construção social coletiva. Petrópolis: Vozes, 2013. p. 369-398.

MUNARIM, A. Educação dos trabalhadores do campo e da cidade e política educacional: desafios centrais. In: PALUDO, C. (Org.). Campo e cidade em busca de caminhos comuns. Pelotas: UFPel, 2014. 203 p.

PALUDO, C. Educação popular em busca de alternativas: uma leitura desde o campo democrático e popular. Porto Alegre: Tomo Editorial/Camp, 2001. 272 p.

. Educação popular e movimentos sociais. In: ALMEIDA, B.; ANTONIO, C.; ZANELLA, J. (Org.). Educação do campo: um projeto de formação de educadores em debate. Cascavel: Edunioeste, 2008. p. 39-53. 
PUIGGRÓS, A. De Simón Rodríguez a Paulo Freire: educación para la integración latinoamericana. Bogotá: Convênio Andrés Bello, 2005. 131 p.

. La disputa por la educación en América Latina: hegemonía y alternativas. In: SOLLANO, M. G.; ZASLAV, M. C. (Org.). Reconfiguración de lo educativo en América Latina: experiências pedagógicas alternativas. México: Unam, 2014. p. 103-120.

RODRÍGUEZ, S. Inventamos o erramos. Caracas: Monte Ávila, 1979. 240 p.

SECRETARIA-GERAL da Presidência da República. Marco de Referência da Educação Popular para as Políticas Públicas. Brasília: Secretaria-Geral, 2014. Disponível em: < http://conae2014. mec.gov.br/images/pdf/MarcodeReferencia.pdf>. Acesso em: 12 nov. 2017.

SILVA, R.; MACHADO, E. R. Uma teoria geral para a educação popular e a educação social? Aproximações empíricas, teóricas e metodológicas. In: STRECK, D.; ESTEBAN, M. T. (Org.). Educação popular: lugar de construção social coletiva. Petrópolis: Vozes, 2013. p. 128-142.

STRECK, D. A educação popular e a (re) construção do público: há fogo sob as brasas? Revista Brasileira de Educação, Rio de Janeiro, v. 11, n. 32, p. 272-284, maio/ago. 2006.

Entre emancipação e regulação: (des)encontros entre educação popular e movimentos sociais. Revista Brasileira de Educação, Rio de Janeiro. v. 15, n. 44, maio/ago., 2010 b.

. Paulo Freire e a consolidação do pensamento pedagógico na América Latina. In:

(Org.). Fontes da pedagogia latino-americana: uma antologia. Belo Horizonte: Autêntica, $\overline{2010 a .}$ 459 p.

STRECK, D.; ESTEBAN, M. T. Apresentação. In: STRECK, D.; ESTEBAN, M. T. (Org.). Educação popular: lugar de construção social coletiva. Petrópolis: Vozes, 2013. 408 p.

STRECK, D. et al. Educação popular e docência. São Paulo: Cortez, 2014. 203 p.

STRECK, D. Territórios de resistência e criatividade: reflexões sobre os lugares da educação popular. In: STRECK, D.; ESTEBAN, M. T. (Org.). Educação popular: lugar de construção social coletiva. Petrópolis: Vozes, 2013. p. 356-368.

TORRES, A. A educação popular como prática política e pedagógica emancipatória. In: STRECK, D.; ESTEBAN, M. T. (Org.). Educação popular: lugar de construção social coletiva. Petrópolis: Vozes, 2013. p. 15-32

TORRES. A. La educación popular: trayectoria y actualidad. Bogotá: El Buho, 2008. 151 p.

TSCHAJANOW, A. W. Die Sozialagronomie, ihre Grundgedanken und Arbeitsmethoden. Berlin: Paul Parey, 1924.

VASCONCELOS, E. M. Educação popular em saúde. De uma prática subversiva a uma estratégia de gestão participativa das políticas públicas de saúde. In: STRECK, D.; ESTEBAN, M. T. (Org.). Educação popular: lugar de construção social coletiva. Petrópolis: Vozes, 2013. p. 110-127. 
WEINBERG, G. Modelos educativos en la historia de América Latina. Buenos Aires: A-Z Editora, 1984. 221 p.

Submetido em 21 de dezembro de 2017. Aprovado em 20 de fevereiro de 2018. 